\title{
A Provenance Model for Quantified Self Data
}

\section{Andreas Schreiber}

Department for Intelligent and Distributed Systems German Aerospace Center (DLR), Cologne/Berlin 


\section{Motivation}

Use Cases

Quantified Self $(n=1)$
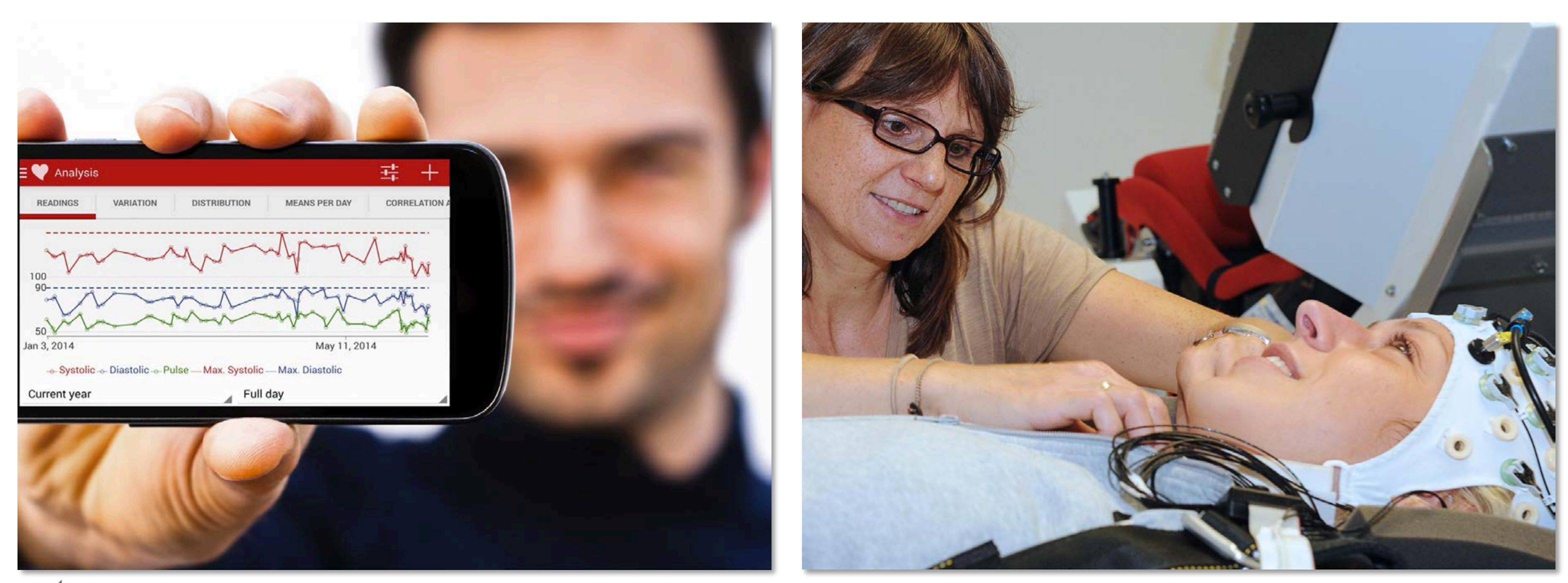

Medical Trials $(n>1)$ 


\section{Motivation}

More Use Cases

Telemedicine

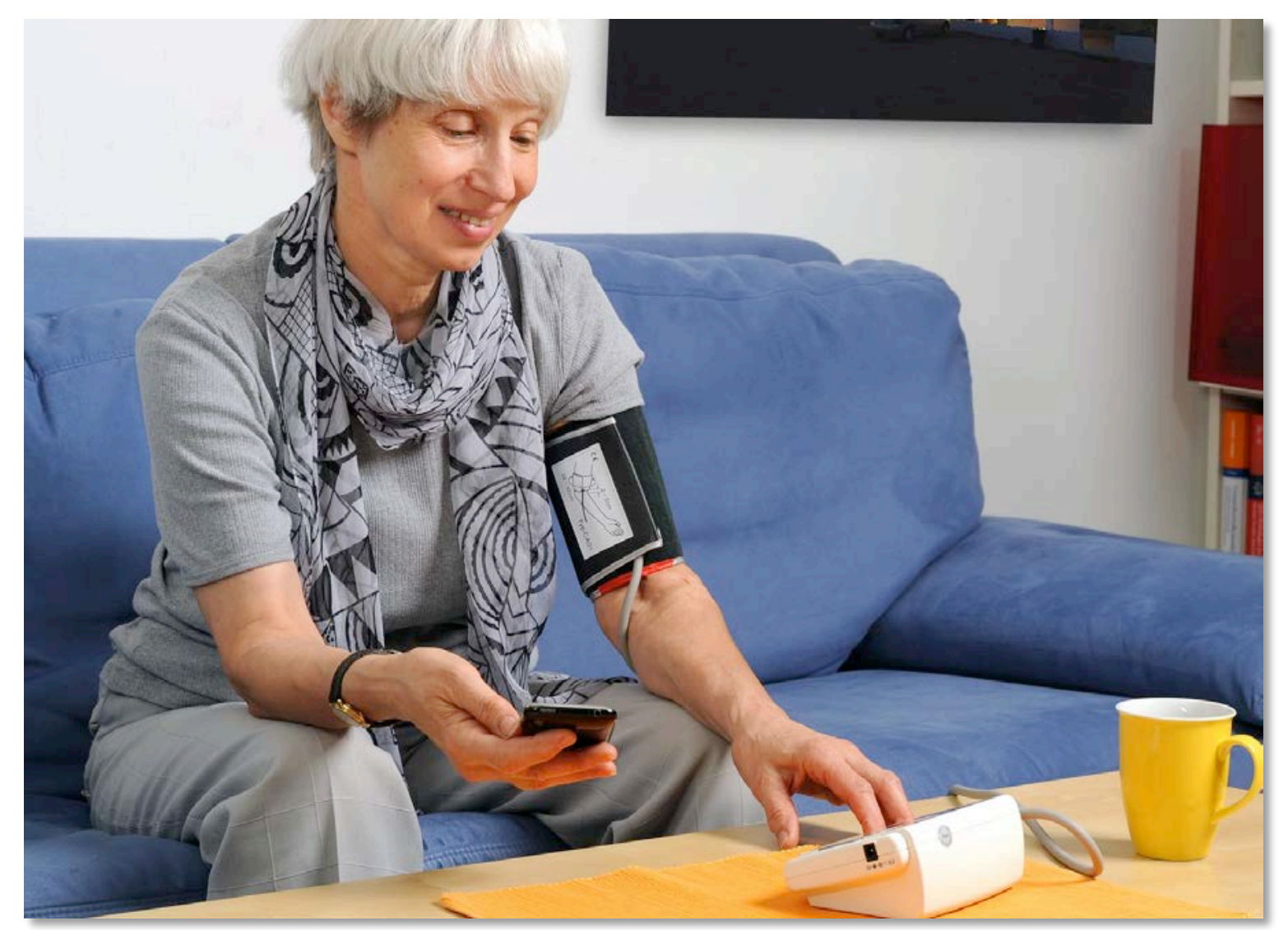

Medical experiments

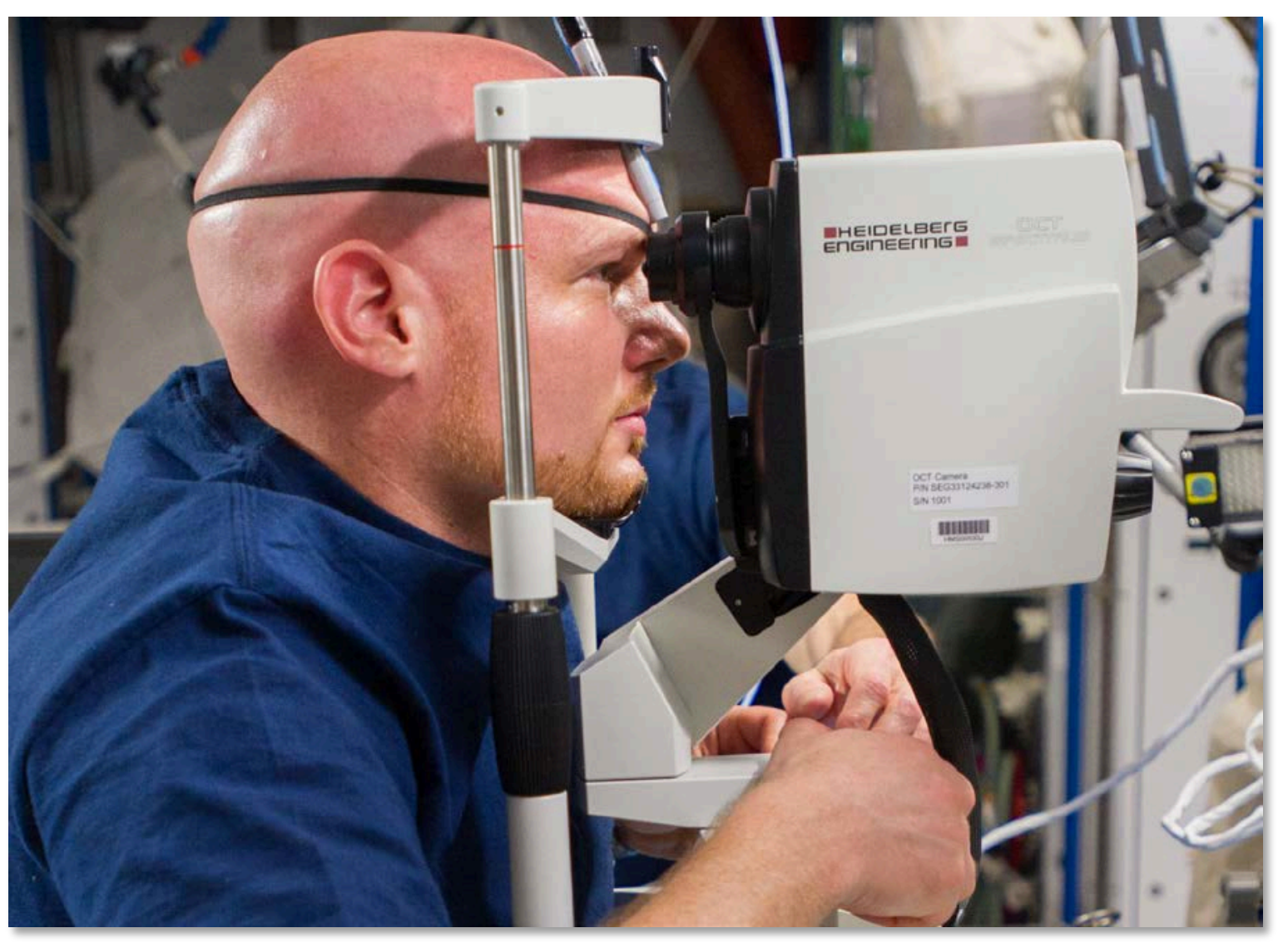




\section{Motivation}

\section{Understand, how data has been produced, processed, stored, accessed, ...}

It started at the Breakout Session on Mapping Data Access (2014 QS Europe Conference, Amsterdam) https://forum.quantifiedself.com/t/breakout-mapping-data-access/995
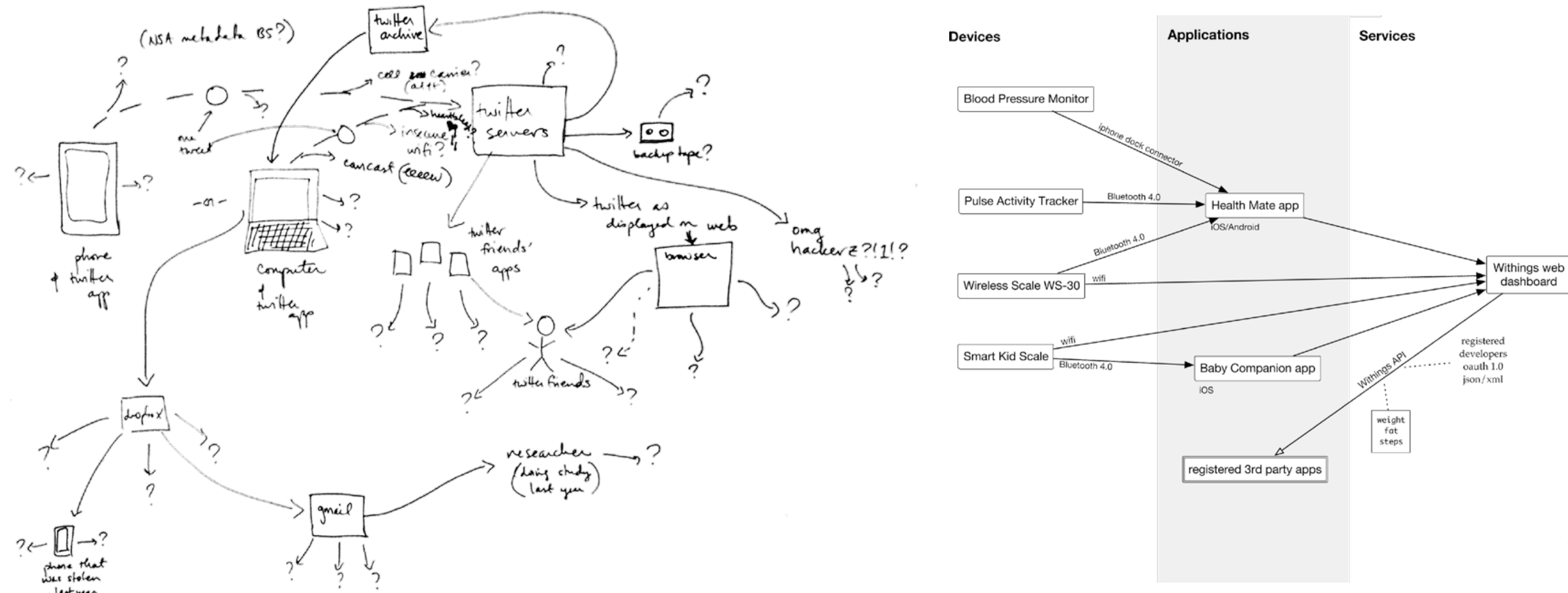


\title{
Motivation
}

\section{(Provenance) Questions}

\section{Entity-focused}

- What data about the user were created during the activity X?

- What data about the user were automatically generated?

-What data about the user were derived from manual input?

\section{Activity-focused}

- Which activities support visualization of the users data?

- In which activities can the user input data?

-What processes are communicating data?

\section{$>$ Data}

\section{$>$ Apps and Services}

\section{Agent-focused}

- What parties were involved in generating data $X$ ?

- What parties got access on data X?

\author{
$>$ Access and Privacy
}

- Can other parties see user's data X? 


\section{Provenance}

Definition

Provenance is information about entities, activities, and people involved in producing a piece of data or thing, which can be used to form assessments about its quality, reliability or trustworthiness. 


\section{PROV}

\section{W3C Specification for Provenance}

\section{$W B^{-S e m a n t i c}$}

W3C Provenance Working Group: https://www.w3.org/2011/prov

\section{PROV}

- The goal of PROV is to enable the wide publication and interchange of provenance on the Web and other information systems

- PROV enables one to represent and interchange provenance information using widely available formats such as RDF and XML

\section{PROV Family of Documents}

- PROV-O: PROV Ontology

- PROV-DM: PROV Data Model

- PROV-N: PROV Notation

- PROV-CONSTRAINTS: PROV Constraints

- PROV-AQ: Accessing and Querying

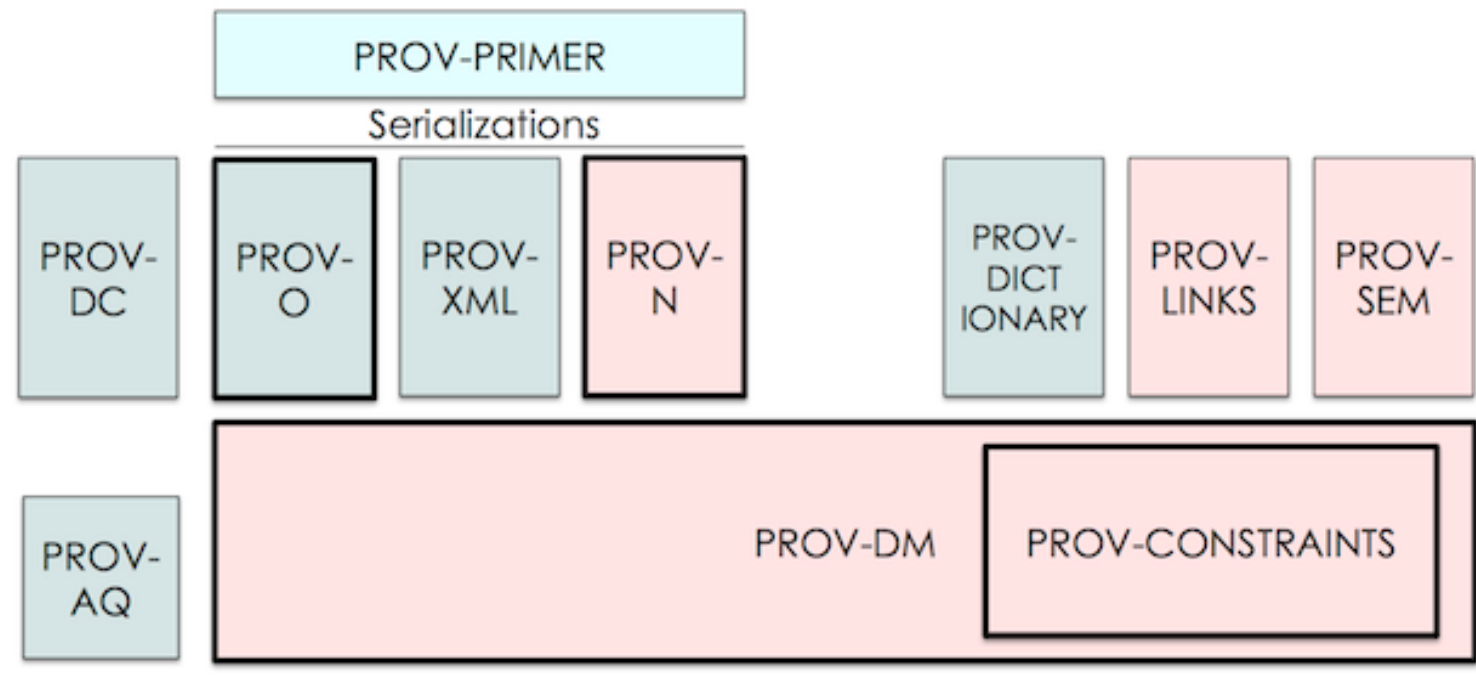




\section{Overview of PROV}

\section{Key Concepts}

\section{Entities}

- Physical, digital, conceptual, or other kinds of things

- For example, documents, web sites, graphics, or data sets

\section{Activities}

- Activities generate new entities or make use of existing entities

- Activities could be actions or processes

\section{Agents}

- Agents takes a role in an activity and have the responsibility for the activity

- For example, persons, pieces of software, or organizations

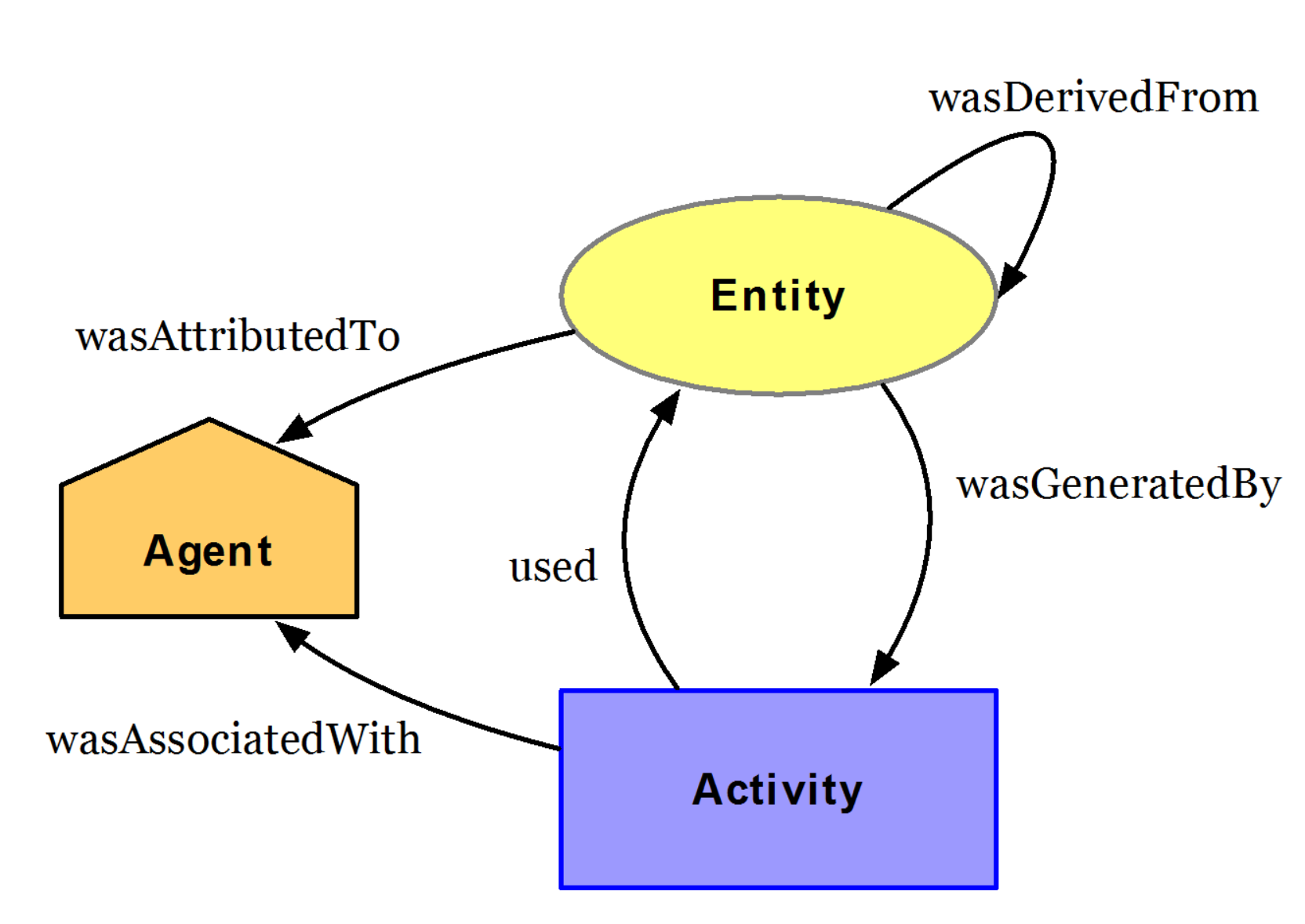

\section{WGE SEmanatic Web}




\section{PROV Example}

\section{Baking a Cake}

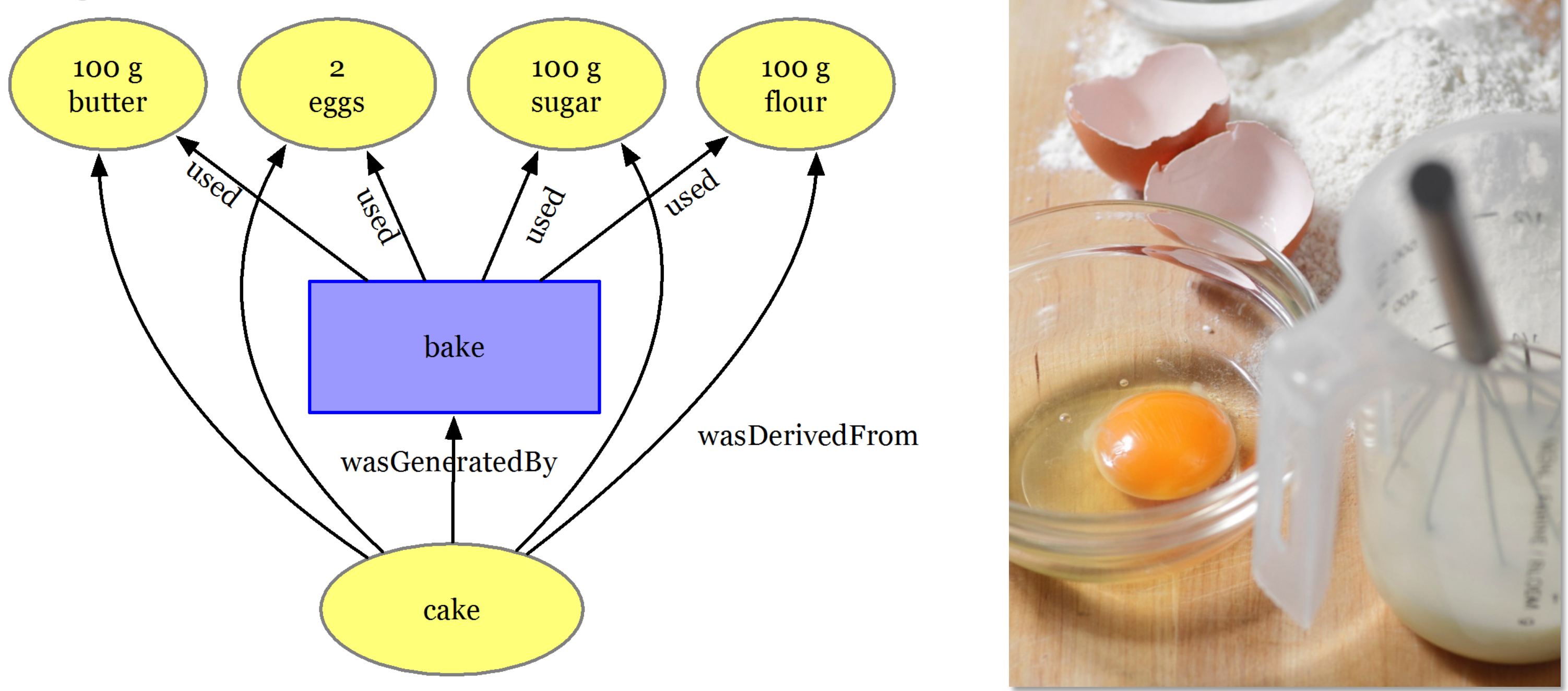




\section{PROV Model for Quantified Self}

\section{Overview}

Five sub models (templates) for basic activities

- Input

- Export

- Request

- Aggregate

- Visualize

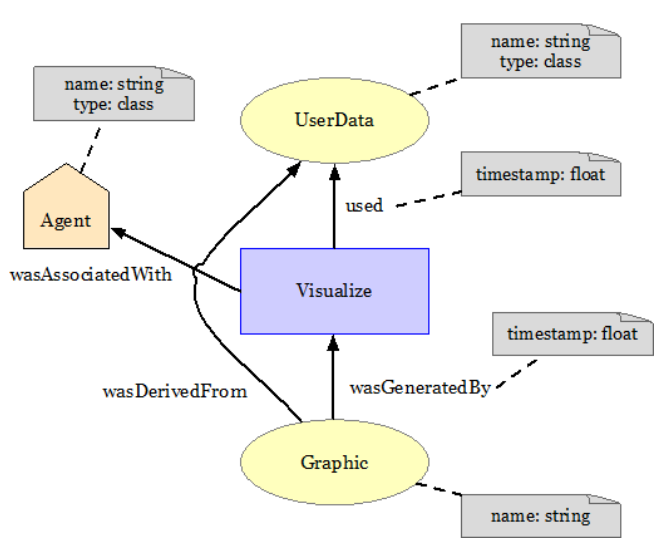

The activities generate or change data that is associated or attributed to Agents

- Users

- Software

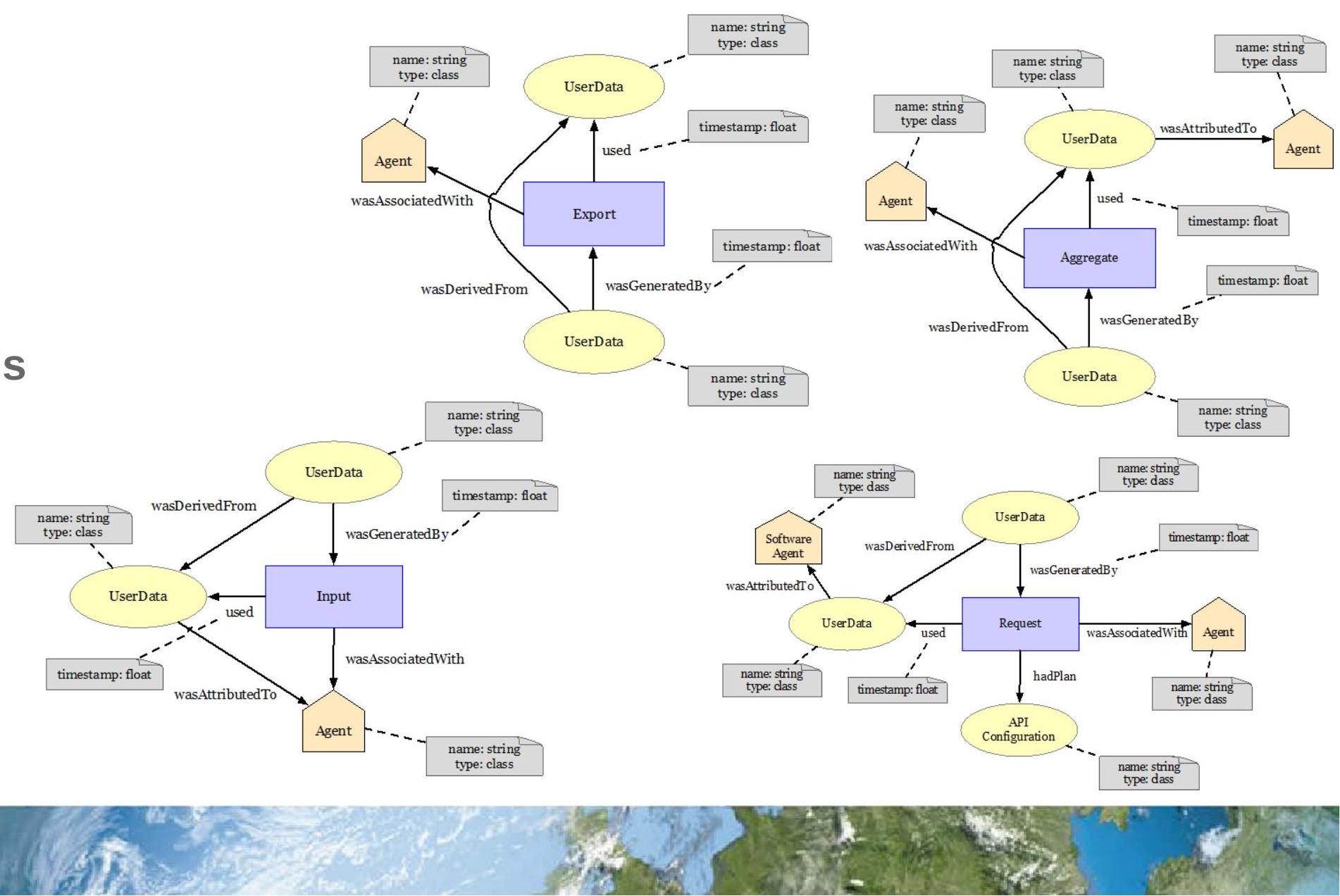




\section{PROV Model for Quantified Self} Input

\section{Getting (raw) data from the user}

- Manual input

- Via sensors

Usually every QS workflow needs such a functionality to record data from the user

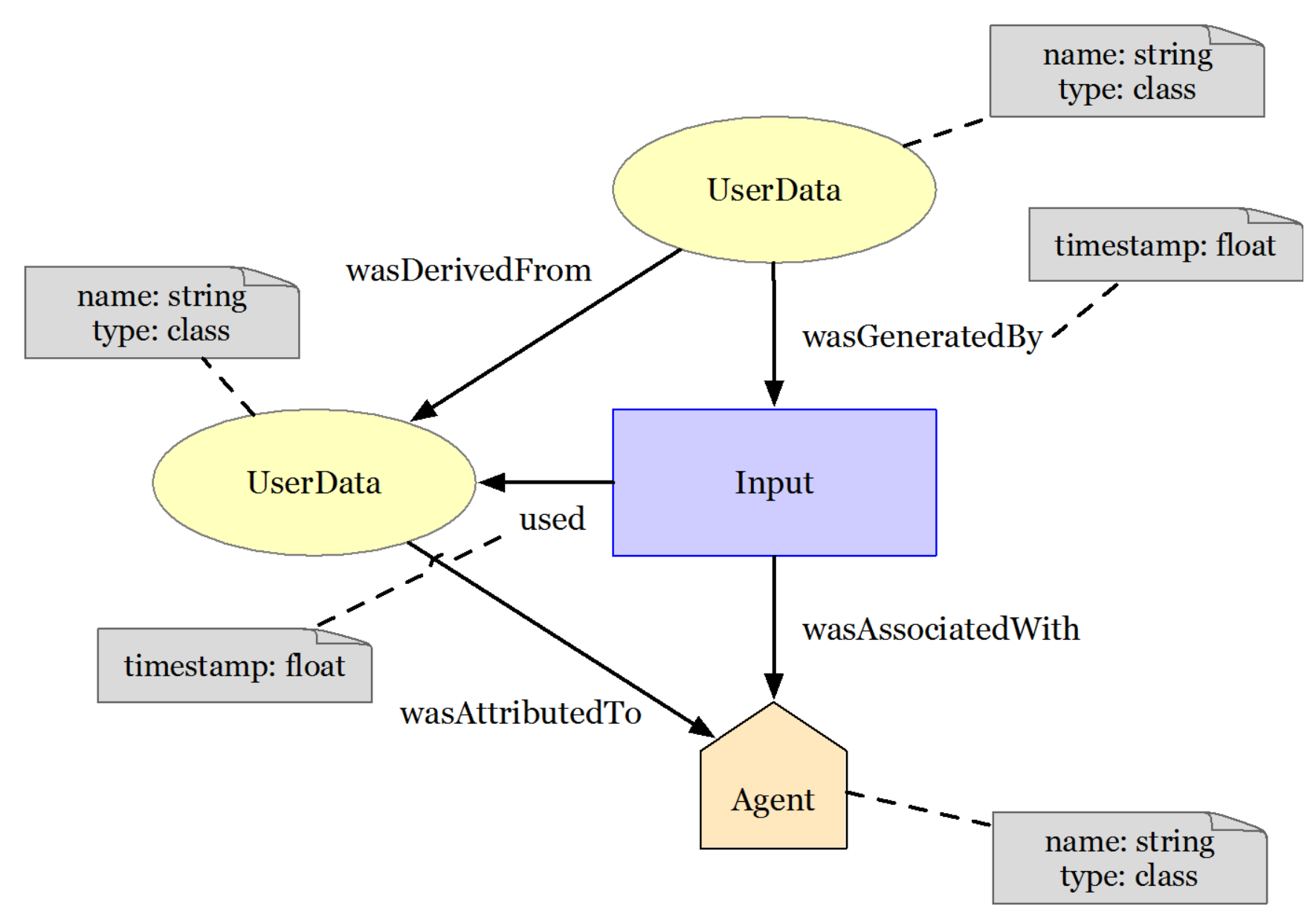




\section{PROV Model for Quantified Self}

\section{Export}

\section{Exports data to other formats}

- Transfer to other systems

- Readable by people

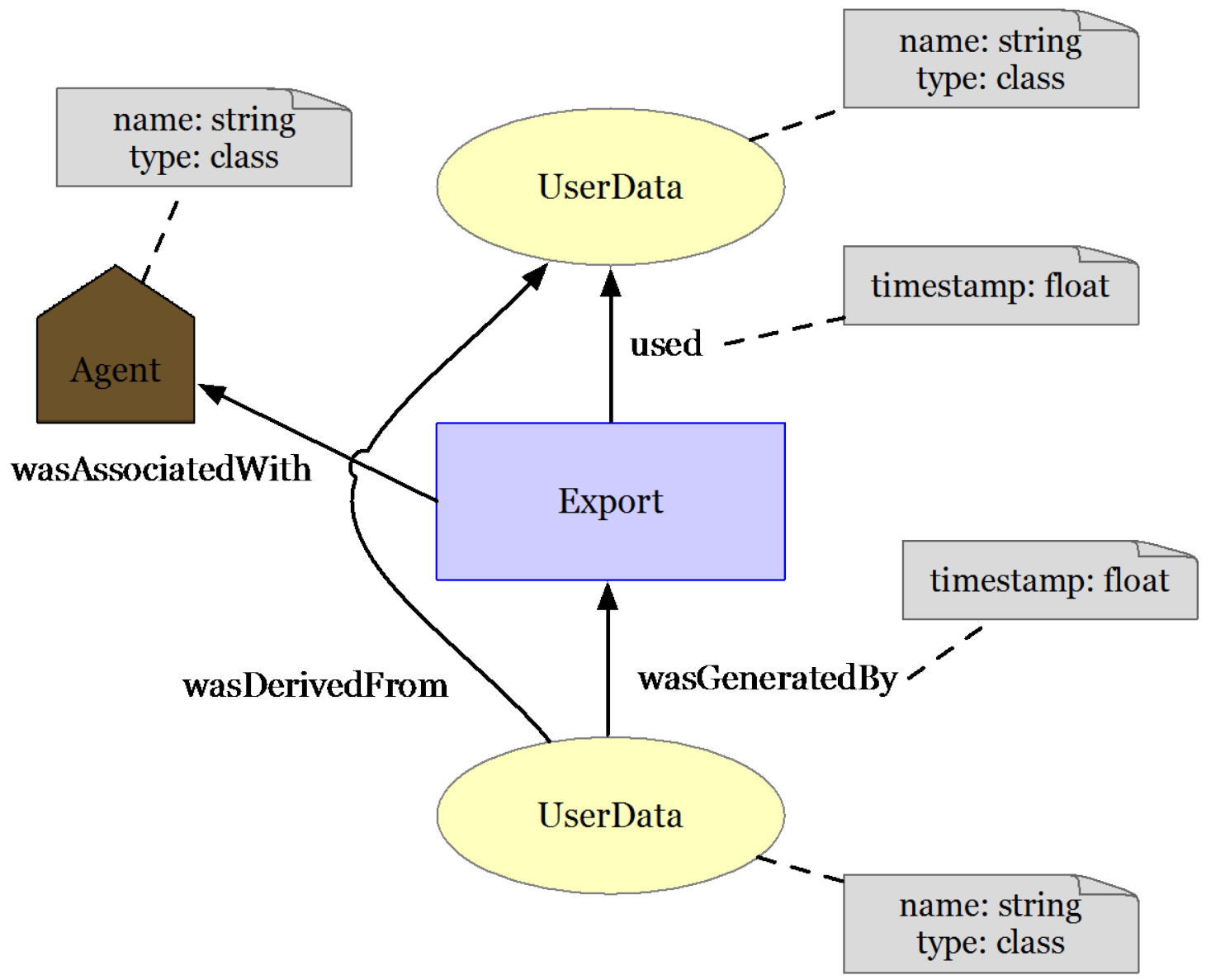




\section{PROV Model for Quantified Self}

\section{Request}

\section{Getting or storing data}

- Web Services

- Cloud Storage

\section{Access via APIs}

- Vendor APIs (Fitbit, Withings, Microsoft etc.)

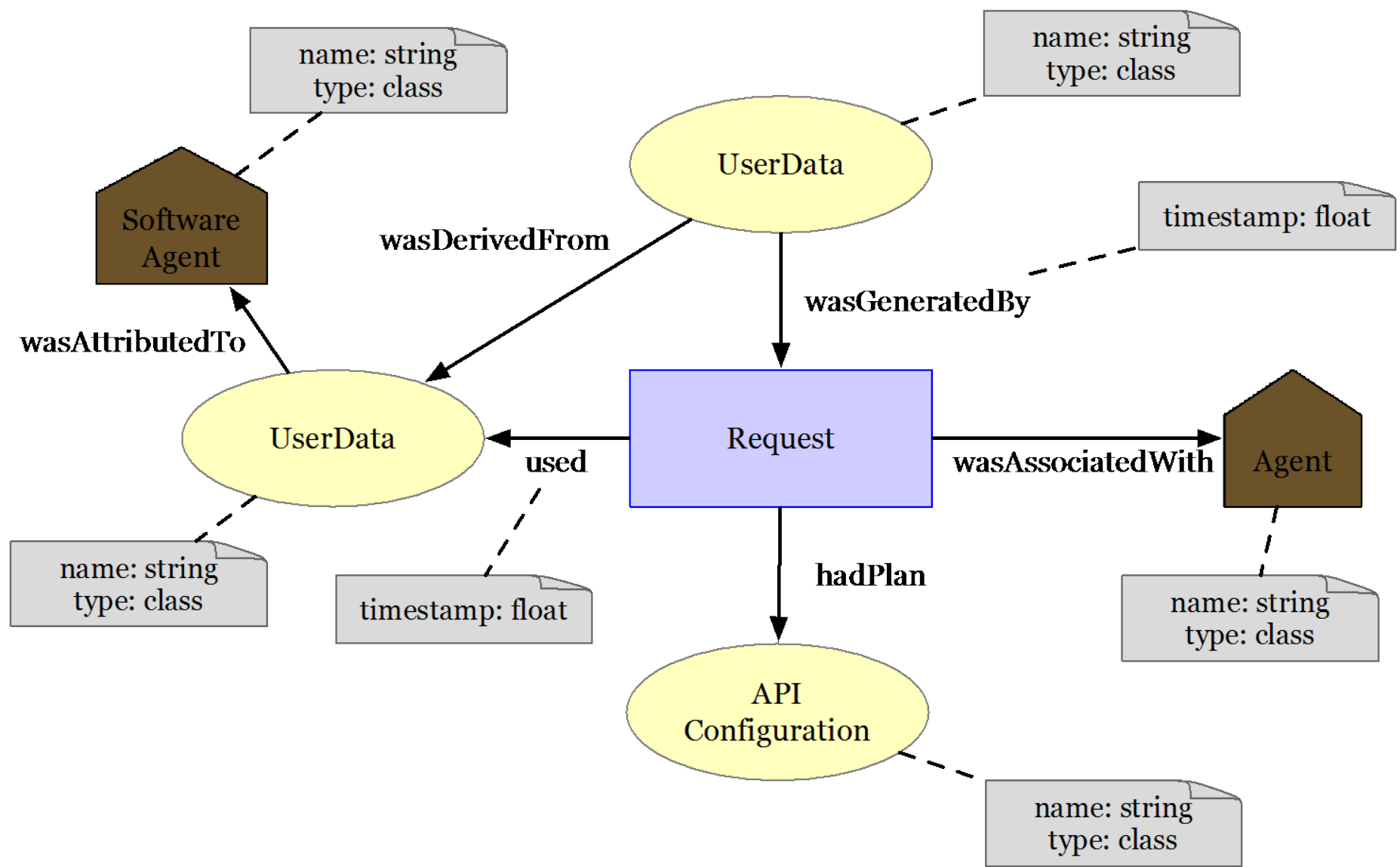




\section{PROV Model for Quantified Self} Aggregate

\section{Combine or analyze data}

- Aggregate different data sets

- Statistical analysis

- Extract knowledge

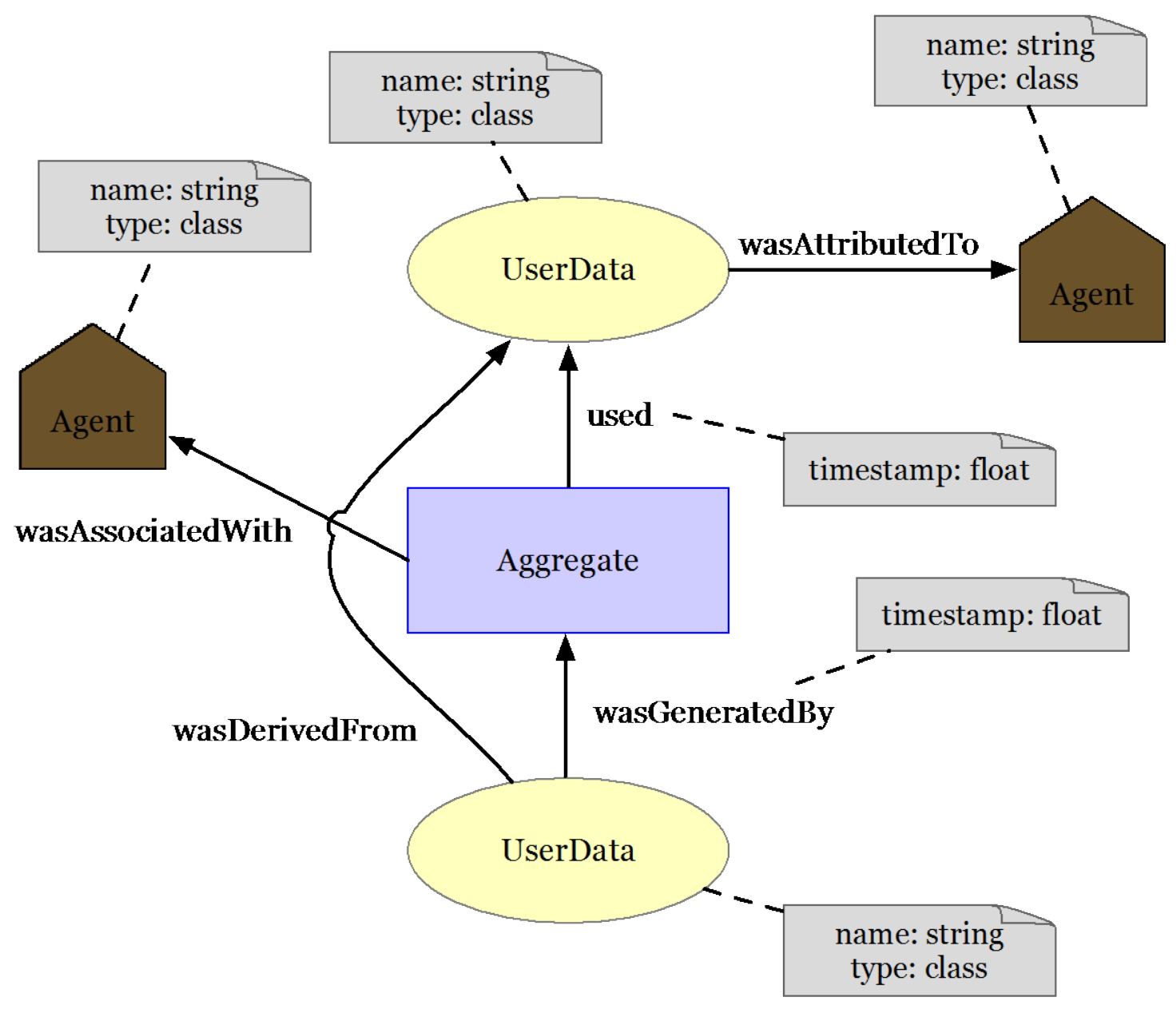




\section{PROV Model for Quantified Self}

\section{Visualize}

\section{Visualize data}

- Time series plots

- Representation of statistical information

- Historical information

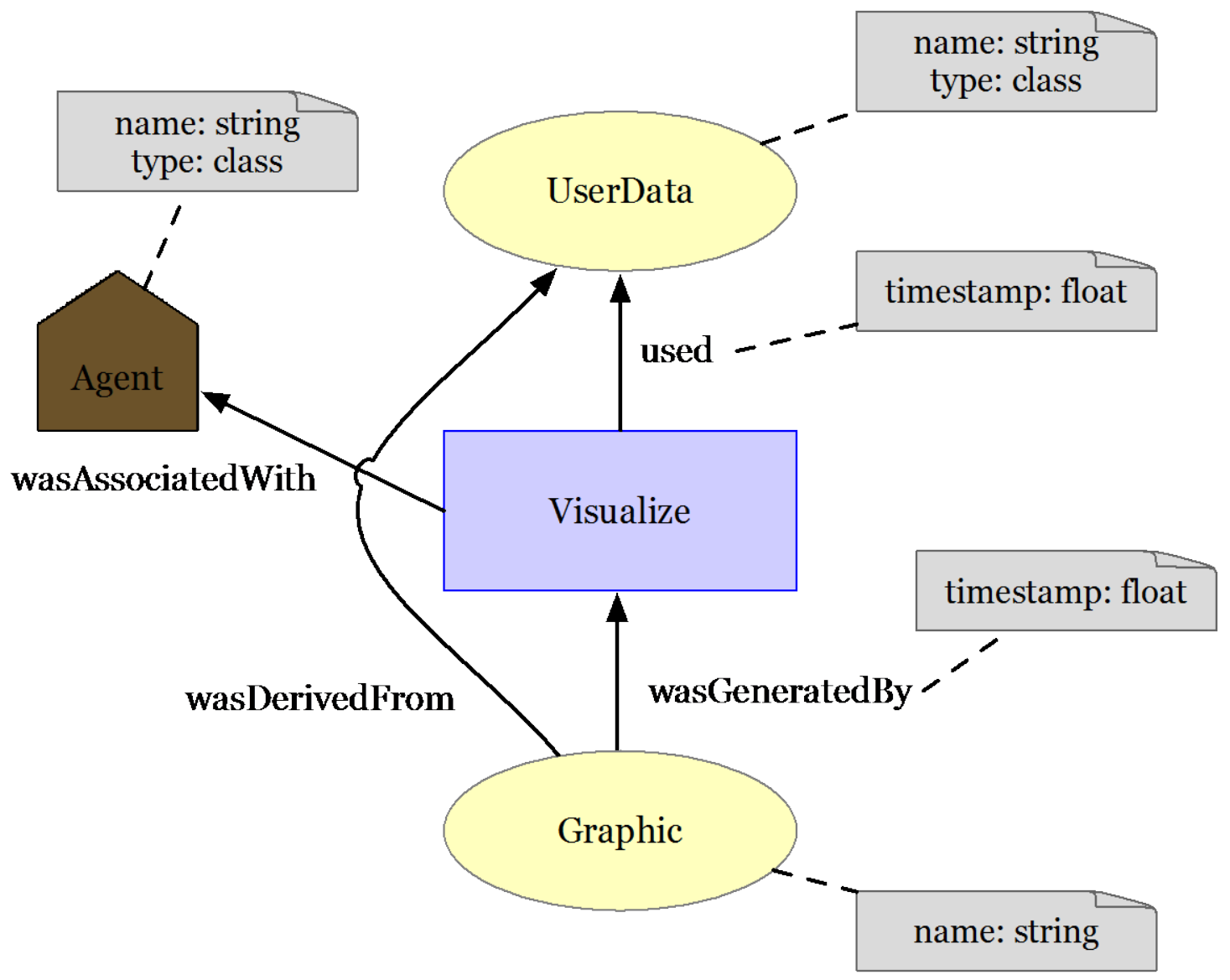




\section{Example}

\section{Weight Tracking}

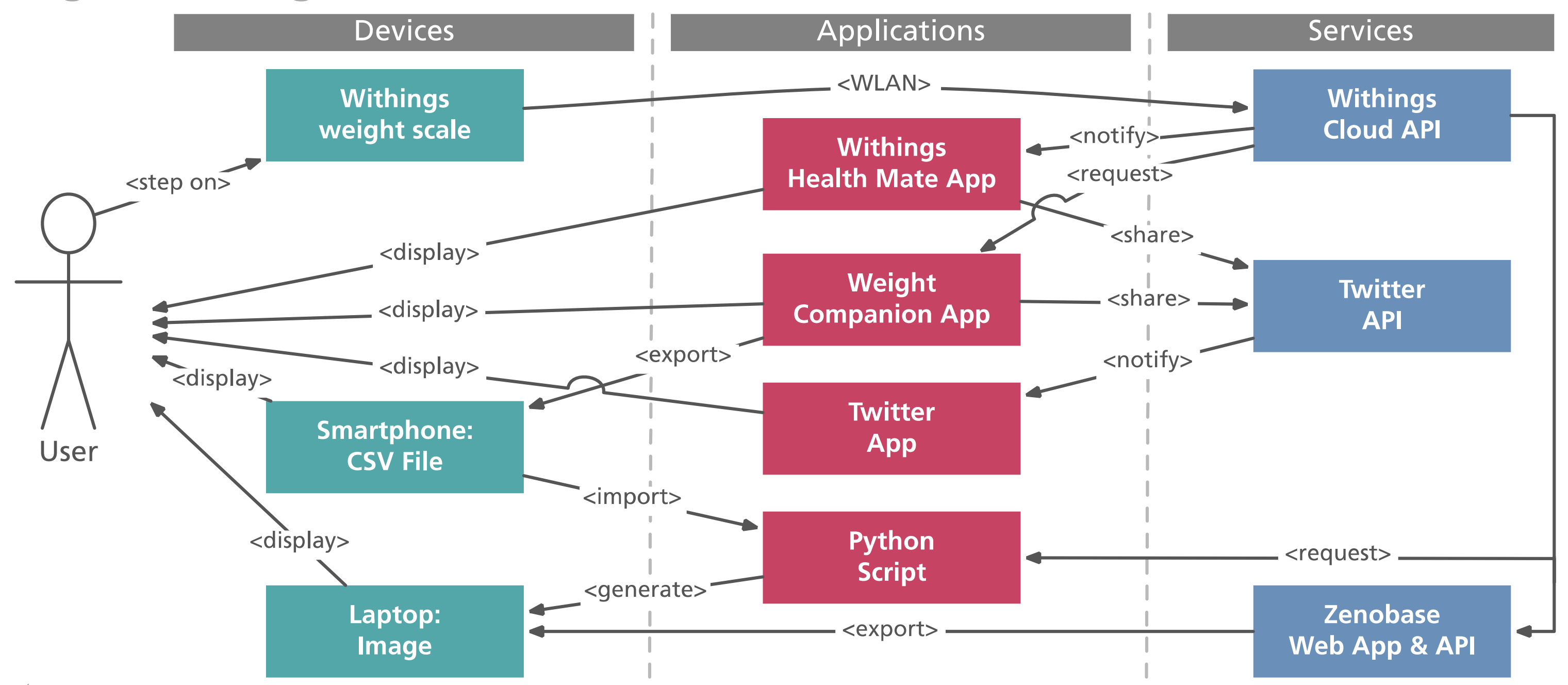




\section{Weight Tracking Example}

\section{Exporting a CSV Fille from an Android App}

name: string

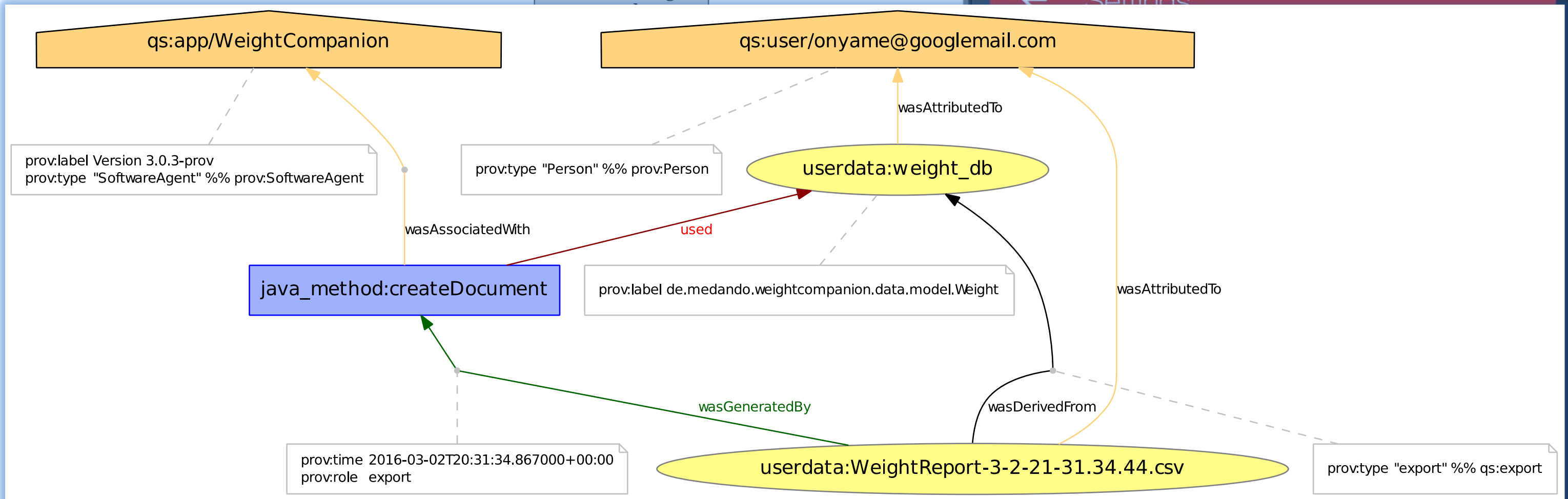

type: class

https://play.google.com/store/apps/details?id=de.medando.weightcompanion 


\section{Weight Tracking Example \\ Visualizing Data with a Python Script \\ Data with a Python Script}

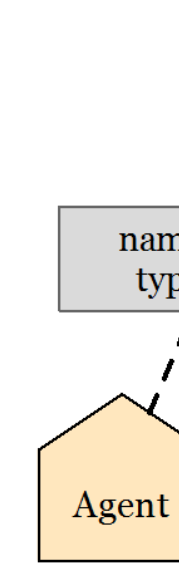
prov $=$ ProvDocument ()

$$
\text { wasAssocia! }
$$

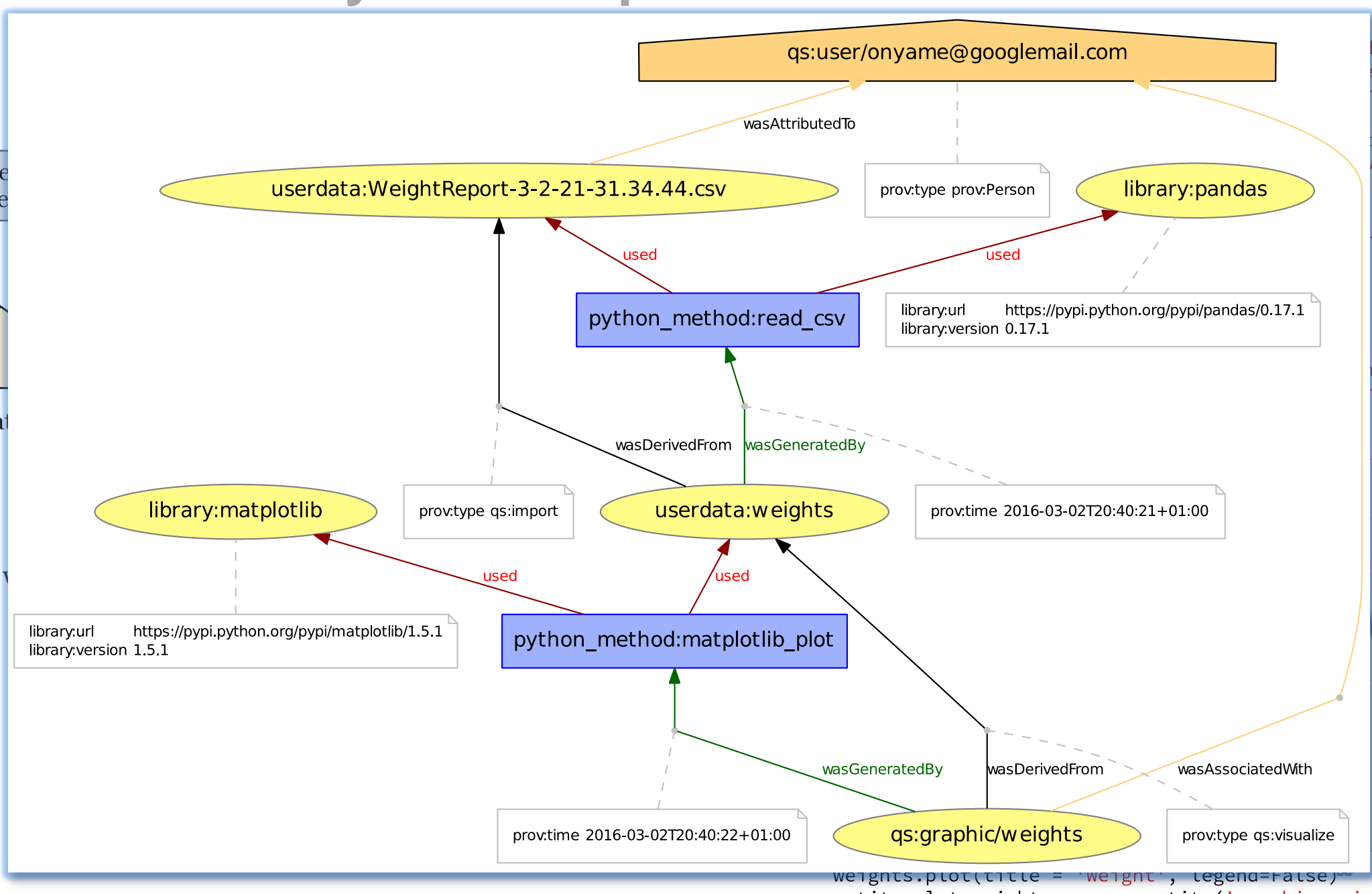

e/qs/'

dlr.de/qs/userdata/' )

de/qs/user/')

dr.de/qs/graphic/')

on.org/pypi/')

python.org')

com', \{'prov:type': PROV['Person']\})

: pd._-_version__)

ion': matplotlib._version__)

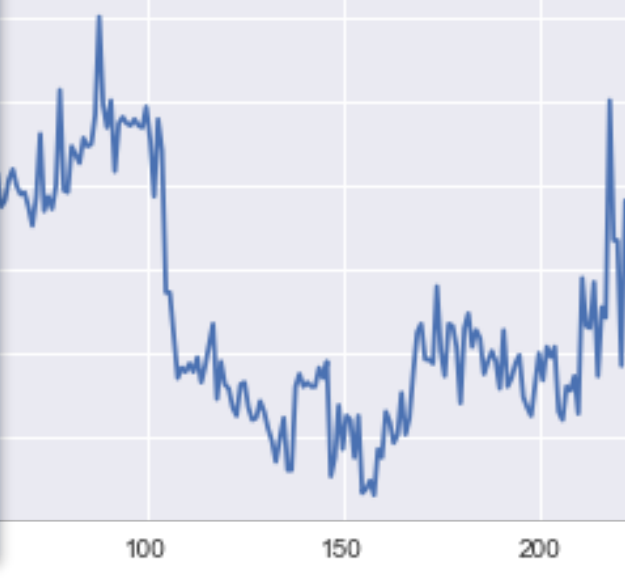




\section{Weight Tracking Example} Merged Provenance

Date, Time, Weight, Waist, Hip, Device, Commen "Jun 13, 2012", 14:00, 83.7, , , Withings, "Jun 13, 2012", 14:08,79.7, , , withings,
"Jun 15, 2012", 21:59, 82.7, , , Withings, "Jun 15, 2012", 22: 04, 82.7, , , Withings, "Jun 24, 2012", 18:32,86.1, , , Withings, "Jun 26, 2012", $07: 42,80.8$, , , withings, "Jun 27, 2012", 07:40, 81.1, , , Withings, "Jun 29, 2012", 07:34, 79.4, , , Withings, "Jun 30, 2012", 22:12,81.7, , , Withings, "Jul 1, 2012", 11:21,80.6, , , Withings, "Jut 7, 2012",17:04,80.7, , , Withings, "Jut $10,2012 ", 07: 46,81.8$, , , Withings, "Jul 12, 2012", $07: 26,79.4$, , , , withings,

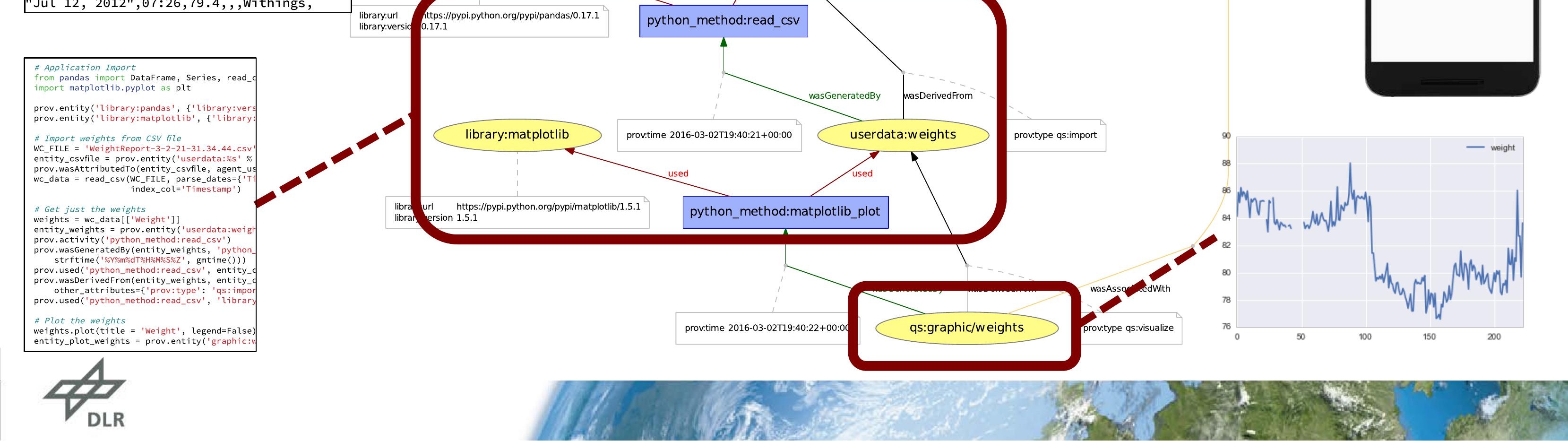




\section{Conclusions}

\section{Summary}

- We collected QS workflows at QS Meetups and QS Conferences

- We used the standardized data model PROV for modeling the provenance of QS and medical workflows

- We evaluated the feasibility with selected QS workflows

Intentionally not mentioned in this talk

- Storing provenance

- Querying provenance

\section{Current and Future Work}

\section{Provenance Templates and Standardization}

- PROV templates for developer of tools and services

- Guidelines and APIs for developers

- Writing a specification

\section{Provenance Analytics and Visualization}

- Traceability of data

- Reproducibility of studies

- Visualization 


\section{Thank You!}

Questions?

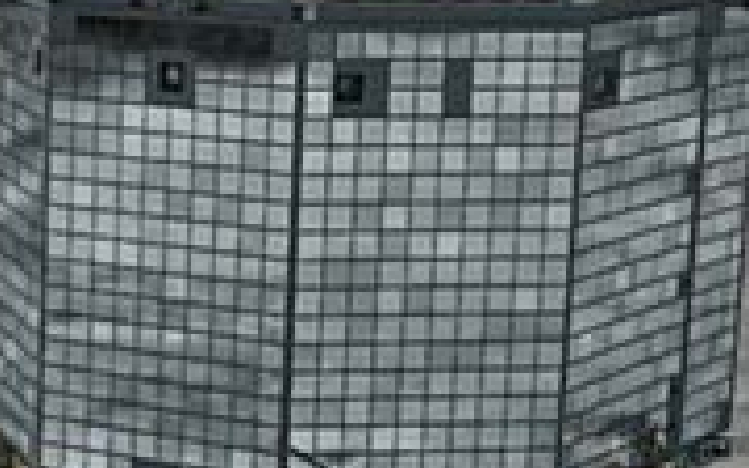

\section{Andreas Sthrejberedlr . de} www BLR de/se 1 Conyame 